\title{
Feeling Wronged: The Value and Deontic Power of Moral Distress
}

\author{
Carla Bagnoli ${ }^{1,2}$ iD
}

Accepted: 23 September 2021 / Published online: 24 November 2021

(c) The Author(s) 2021, corrected publication 2021

\begin{abstract}
This paper argues that moral distress is a distinctive category of reactive attitudes that are taken to be part and parcel of the social dynamics for recognition. While moral distress does not demonstrate evidence of wrongdoing, it does emotionally articulate a demand for normative attention that is addressed to others as moral providers. The argument for this characterization of the deontic power of moral distress builds upon two examples in which the cognitive value of the victim's emotional experience is controversial: the case of micro-aggression, and the case of misplaced distress. In contrast to appraisal and perceptual models of distress, it is argued that its epistemic and normative value is dialogical rather than evidential, in that it presses claims that engage the audience in a normative discussion about the normative standing of the claimant, the proper grounds of the attitude, and the normative standards used to assess them.
\end{abstract}

Keywords Moral Experience $\cdot$ Moral Distress $\cdot$ Reactive Attitudes $\cdot$ Recognition · Microaggression · Justice

\section{Introduction}

The subjective experience of feeling wronged is often reported as an essential aspect of the experience of being wronged, though it is neither a sufficient nor a necessary condition for it. One might feel hurt or crossed without having been offended, and not all injuries and losses are felt. This mismatch is often used to raise doubts regarding the cognitive value of the appeal to the subjective emotional experience of distress, which seems inadequate to serve as evidence of wrongdoing. Hurt feelings can be deceptive and misplaced, and thus they cannot provide a reliable basis from which to establish that somebody has been wronged. While, their occurrence is not adventitiously associated with being wronged, it is

Carla Bagnoli

carla.bagnoli@gmail.com

All Souls College, The University of Oxford, High Street, OX1 4AL Oxford, UK

2 Department of Human Sciences, Università di Modena and Reggio Emilia, Reggio Emilia, Italy 
related to wrongdoing in complex ways. The aim of this paper is to uncover some aspects of this complexity and argue that hurt feelings belong in the large and heterogeneous category of attitudes that Peter Strawson termed "reactive" (Strawson 1962). Though hurt feelings do not react solely to wrongdoing, they do have a distinctive deontic import, and they articulate the moral demands of normative attention that are addressed to others as moral providers, thereby contributing to the social dynamics of ethical and political empowerment.

The outline of my argument is as follows. In Sect. 1, I make explicit the theoretical commitments associated to the category of reactive attitudes in order to argue that the experience of feeling hurt is the appropriate emotional reaction to being wronged and that the emotional articulation and responsiveness to wrongs are fundamental modes of exercising the capacity for moral agency. In Sect. 2, I distinguish two dimensions of emotional reactivity, emotional responsiveness to and engagement with others, as agents endowed with moral powers. In Sect. 3, I propose that moral distress represents a distinctive category of reactive attitudes that articulates the demands of normative attention in virtue of its specific forward-looking and generative reactivity. In Sect. 4, I argue that the cognitive and epistemic import of moral distress is not evidentiary, and that its grounds should be assessed through normative discussion. In Sect. 5 and 6, I discuss two cases in which the appeal to the subjective emotional experience is controversial: the case of micro-aggression, and the case of misguided distress. In these cases, the import of moral distress is deontic, in that the claimants may legitimately claim normative attention even when their grounds for distress are controversial or morally questionable. This is because moral distress as a demand of normative attention generates a generic duty that does not depend on the claimant's purported grounds. Finally, in Sect. 7, I point to two possible further deployments of this category of moral distress that promise to enhance theories of justice based on the principles of practical reason and contribute to the debates in moral epistemology regarding the dialogical-epistemic import of the appeal to the subjective emotional experience.

\section{Being Wronged and Feeling Hurt}

It is ordinarily expected that being wronged is associated with the emotional experience of feeling hurt, though one does not amount to the other. Feeling wronged comes in different emotional guises: someone who has been humiliated feels ashamed, someone who has been robbed feels angry, someone who has been insulted feels indignant, and someone who has been betrayed feels hurt. In the aftermath of a moral wrong, people may experience all of the moral feelings listed above, though in varying combinations and proportions. My working hypothesis is that a distinctive category of hurt feelings, which I shall term "moral distress," are best understood - in line with Peter Strawson's characterization — as "reactive attitudes." "In this section and the next, I make explicit the general theoretical commitments entailed by this categorization of the subjective emotional experience. In Sect. 3 and 4, I

\footnotetext{
${ }^{1}$ Hurt feelings figure among Strawson's reactive attitudes 1962, p. 72. My purpose is to carve a sub-category of hurt feelings, i.e., moral distress, with distinctive deontic powers. I do not claim that this category tracks the ordinary usage in natural language but that, by sharpening this concept, we can identify a paradigmatic forward-looking function of some reactive attitudes, which has been overshadowed by the predominant discussion over backward-looking reactive attitudes.
} 
argue in more detail the reasons why moral distress should be considered a distinctive subcategory of reactive attitudes, and I discuss what follows from this argument.

Strawson introduced the category of reactive attitudes in an attempt to argue that ascriptions of responsibility are inextricably tied to emotional attitudes of a distinctive sort and are rooted in mutual normative expectations and demands. ${ }^{2}$ As I understand it, Strawson's view is that reactive attitudes respond to they and press demands of respect and recognition of normative standing in the moral community- i.e., in the abstract community of agents who are endowed with moral capacities. Unlike other varieties of emotional attitudes, reactive attitudes constitute a moral nexus of deontic relations, that is, relations that are articulated in terms of obligations, prohibitions, and permissions, and that bind all and only the active members of the moral community to one another. In virtue of their normative standing, moral agents as such can address each other with proper authority. ${ }^{3}$

The category of reactive attitudes is, admittedly, broad and heterogeneous. It includes negative and positive moral feelings such as resentment and gratitude, blame and praise, indignation and admiration, and regret and affirmation. These emotional attitudes vary in their temporal orientation, and presumably also in their moral connotation and their scope of application. Thus, one might question whether they can be given a unified account (Bennett 1980). In what follows, I shall focus on the deontic function of reactive attitudes, which is recognized to be fundamental even by those who note the difficulty of giving a unified account of reactive attitudes in such terms. ${ }^{4}$

On the basis of this deontic characterization, we can make explicit the conditions that may warrant reactive attitudes to carry demands and normative expectations. On the construal above, there are two general conditions of warrant for the whole category of reactive attitudes; both concern the subject and the target of the attitudes. First, there are conditions concerning the normative standing of the subjects as active participants in the moral community, and their capacity for supporting their taking an attitude toward others on the basis of justificatory reasons. Second, there are general conditions concerning the normative standing of the addressees, as active participants of the moral community, and their capacity to understand, respond to, and engage with the attitudes taken by others on the basis of justificatory reasons. More specifically, reactive attitudes respond to actions as manifestations of the (ill or good) quality of the will, ${ }^{5}$ and engage with others as agents with moral powers and moral interlocutors who are bound by the norms of reciprocity. The first condition ensures

\footnotetext{
2 Watson writes that "the negative reactive attitudes express a moral demand, a demand for reasonable regard”, Watson 1987, 264. See also Wallace 1994, p. 11; and Darwall 2006.

3 This is a second-personal authority to make demands, which corresponds to the capacity to understand, relate, and engage with others as persons capable of exchanging and acting on reasons.

${ }^{4}$ See, e.g., Bennett 1980; Mason 2017, p. 154.; Macnamara 2013 objects to the thesis that reactive attitudes articulate demands. I do not dispute that the category of reactive attitudes is heterogeneous but I share the view that their fundamental function is deontic and articulates second-personal demands.

5 This is Strawson's definition, Strawson 1962, § 3. This definition should not be taken to endorse a Kantian conception of the self; in fact, there are competing accounts of the will, which depart from the Kantian account. Reactive attitudes target actions as manifesting and expressive of agency, and may be taken to be equivalent to expressions of character, in a way that does not commit to any specific philosophical account of character or will. The point I am making is that hurt feelings are reactive attitudes - i.e., attitudes that respond to others as having normative standing as rational agents - is general enough to accommodate different normative perspectives on agency and personhood-including, e.g., relational, Frankfurtian, and Humean views. I would like to thank a referee for raising a worry about the Kantian presupposition of my argument.
} 
that the subjects who express reactive attitudes do so with proper authority, as active participants in the moral community. This sort of authority does not depend on any special faculty or role; it is merely the authority that is derived from being an agent endowed with moral and rational capacities, in the most generic sense. ${ }^{6}$ The second condition can be understood as narrowing down the domain of objects that can be the appropriate targets of reactive attitudes to the quality of the will. In fact, it identifies the quality of the will as the seat of moral agency. ${ }^{7}$ Thus, taken together, these conditions establish that persons are the intentional objects of reactive attitudes, where the condition of being a person is to possess a will.

Both conditions refer implicitly to the moral community as being governed by norms and to persons as being susceptible to being guided by norms and capable of exchanging reasons. On this broad construal, then, reactive attitudes make sense from within a web of normative practices of mutual accountability, in which subjects recognize and relate to one another as fellow participants. They pertain to the participant stance that is characteristic of personal (emotional and rational) engagement with others as moral agents. ${ }^{8}$

There are different ways of construing and further specifying the requirements that pertain to the moral community, but for the purposes of this discussion, it suffices to presume that reactive attitudes are constitutive of deontic moral relations among agents with normative standing and that they must be justified by reasons that their peers can share. ${ }^{9}$ The basic conditions that for warrant reactive attitudes are that the claimants have the authority to address others as peers and that the addressees have the capacity to understand and comply with such a request while also remaining entitled to question its warrant. Since the moral community does not coincide with any one concrete community, but is instead the abstract community of all agents with normative standing, these conditions are satisfied by any agent with moral powers and capacities to actively engage in normative practices and entertain reasons for action; no special epistemic authority based on special faculties or roles is required.

\section{Two Dimensions of Emotional Reactivity}

This interpretation accounts for the fact that there are normative expectations that one should feel, for example, resentful and angry wronged. Resenting a wrong is not only probable, typical or normal under specified circumstances; it is also appropriate. This is because attitudes are not passive occurrences; they are expressions of agency that, importantly, articulate one's self-understanding as an agent who is endowed with moral powers and normative standing. Agents endowed with moral and rational powers are capable of taking attitudes toward particular objects, and they can justify these on the basis of reasons. They are susceptible to requests of warrant, can be questioned about the reasons that ground their

\footnotetext{
${ }^{6}$ There are varieties of conceptions of moral agency and moral authority that vindicated this function, see, e.g., Darwall 2006, pp. 58, 60, and Wallace 2019. My purpose here is to underline the relation between reactive attitudes and the requisite authority of persons as capable of moral agency.

${ }^{7}$ Moral agents are addressed as "wholes", see Bennett 1980, p. 33.

${ }^{8}$ On the definition of the participant stance in contrast to the objective stance, see Strawson 1962, p. 67. On the second-personal interpretation of the practical stance, see Darwall 2013, pp. 10-11. On the relevant notion of emotional engagement, cf. Slaby and Wüschner 2014, and Solomon 2004.

9 This generic statement suffices to exclude a broad category of the wrong kind of reasons as grounds of reactive attitudes. For a different construal of the right kind of reasons, see Darwall 2006, pp. 15-16, 20-22.
} 
taking a particular attitude toward other agents, and are capable of assessing such grounds according to normative standards. They are also entitled to question and dispute the normative standards upon which the grounds of their attitudes are assessed by others. Thus, attitudes are a category of affective dispositions for which agents are morally and rationally accountable. They lie at the core of normative practices, but they are themselves governed by normative standards that in turn govern their appropriateness and their functions.

Arguably, the expressive articulation of reactive attitudes fulfills different normative functions in a community that is governed by norms. ${ }^{10}$ It communicates to others (e.g., transgressors, bystanders, the community at large or its representatives) that somebody with normative standing in the same community feels wronged, but more importantly, it also carries demands of normative attention and thus seeks a normative engagement with others. In the aftermath of wrongdoing, it is appropriate that victims should demand that a respectful relationship be restored: that the wrongdoers apologize, or that the bystanders condemn the wrongs that were committed and take a stand regarding how they must be repaired.

However, the reactivity of reactive attitudes should not be cast uniquely in terms of responsiveness, as if the emotions were akin to perceptions or subjective appraisals. ${ }^{11}$ Reactive attitudes seek a normative response from others and thus, in contrast to responses to, for example, particular aspects of the situation, reactive attitudes are modes of engagingthat is aimed at relieving moral distress. More specifically, reactive attitudes seek responses from others qua agents who are endowed with moral powers and bound by the norms of reciprocity. Such a response may take the guise of a co-reactive attitude. ${ }^{12}$

Furthermore, the emphasis on the expression of distress should not be taken to suggest that the emotional experience of reactive attitudes can be set apart from the moral experience, i.e., the experience of feeling wronged or disappointed in one's expectations. In some cases, the emotional reaction is the direct result of having been wronged, in the sense that to hurt somebody's feelings and cause them distress may be just the specific way in which they have been wronged. Hurt feelings are not the effect or byproduct of being wronged, but of the modality in which victims are wronged. Thus, the presence of hurt feelings is of normative relevance, and its relation to wrongdoing is not adventitious and fortuitous. Correspondingly, the normative expectation that feeling hurt should be concomitant with the experience of being wronged indicates that the experience of being wronged is, at least partly, an emotional experience (i.e., the experience of feeling wronged).

Finally, the capacity for negative and positive reactive attitudes, is not merely associated with, but is constitutive of, the capacity for understanding and articulating the distinction between right and wrong. Thus, when victims of injustice do not feel wronged, their capac-

\footnotetext{
${ }^{10}$ I draw a contrast between the "expressive articulation" of reactive attitudes and their "verbal articulation" because I want to emphasize that emotional attitudes provide for an emotional articulation of the situation and that they are directly related to the exercise of rational and moral agency. The expression of reactive attitudes points to demands whose verbal articulation subsequently becomes the object of a normative discussion.

${ }^{11}$ On the appraisal model, see Mason 2017; on the perceptual model see Tappolet 2018.

12 The constitutive sensitivity of attitudes to norms, and their capacity to be held on account of reasons is noted by Darwall 2006, pp. 157-158. Likewise, I consider attitudes to be sensitive to reasons and governed by norms, but unlike Darwall and many others, I do not treat attitudes as "mental states". To highlight the phenomena of co-reactivity, it is necessary to pay attention to the dynamic and temporal structure of reactive attitudes. By treating reactive attitudes as dynamic rather than static, and as sensitive to normative reasons rather than as causal episodes, we are in a better position to understand how they can generate a normative discussion, rather than being forms of receptivity or perceptions of wrongs. On the notion of emotional articulation, see Taylor 1985, and Slaby 2014.
} 
ity to understand, recognize, and appropriately respond to wrongs comes into question and an explanation becomes necessary. It might be that the victims have been violated repeatedly, and so often, that they have adjusted to such dire circumstances and no longer appreciate the moral import of what has been done to them. In the case of internalization of and adaptation to oppressive schemas, victims' emotional unresponsiveness to wrongs might be a defensive strategy they have learned in order to defuse the impact of recurring offenses. However, lowering one's reactivity to wrongs, and thus lowering one's normative expectations, are forms of disempowerment that can be self-defeating. The disempowering effects of such defensive attitudes consist in a corrosion of self-respect, which inhibits the victims' capacity to react to wrongs and agential threats or to demand reparation for past wrongs and fair treatment in the future. In sum, the capacity for emotional responsiveness to and engagement with others are indispensable for the full exercise of moral agency. ${ }^{13}$

\section{The Open Reactivity of Moral Distress}

What is the specific function of a reactive attitude of moral distress? Reactive attitudes are attitudes that react to others as capable of rational and moral agency. ${ }^{14}$ They react to agents for what they ought to have done in the past, but also for what they could do in the future. In my view, the category of moral distress carves a space among reactive attitudes that govern deontic moral relations, in contrast to those that are backward-looking and respond to past wrongs. The temporal orientation of moral distress is relevant for qualifying the nature of its reactivity and, correspondingly, the normative dynamics of the interaction that it supports. Moral distress is primarily forward-looking and aimed at producing a social bond by emotional engagement, rather than at responding to a past failure to abide by a norm. ${ }^{15}$

First, moral distress captures an emotional experience that differs from backward-looking attitudes, such as e.g., resentment, and indignation, in that it does not react to the wrongdoer in the way resentment or indignation do, but it more broadly addresses any moral agent who is able of providing moral support, first of all in the guise of normative attention. Agents are not only engaged with insofar as they can act in accordance to norms; they are also engaged with because (and insofar as) they are capable of moral interactions and of paying normative attention to others. In this capacity, moral distress reaches out to the wrongdoer, but also the

\footnotetext{
${ }^{13}$ In the case of deontic reactive attitudes, the relevant norms govern the attribution of moral consideration and recognition of normative standing within the community bounds. The normative significance of reactive attitudes depends on normative practices eligible to set the bounds of the moral community. For a critical account of this view, see Bagnoli 2021, cf. McGeer 2012.

14 Strawson 1962, pp. 72, and cf. 64.

${ }^{15}$ It may be objected that moral distress must have also a temporal backward-looking orientation if it really tracks a kind of moral wrong. I reject the view that distress tracks wrong-making properties or that it is causally related to a wrong done in the past. Although moral distress is akin to resentment and indignation, its primary function is to express and alleviate. To this extent, I also dispute that moral distress aims at repair, although reparation may relieve pain. My point is that the category of moral distress aims to generate social bonds by targeting moral providers, rather than by responding to and targeting wrongdoers. Its primary function is to demand attention, rather than repair. Furthermore, it may be noted that other reactive attitudes (such as, e.g., resentment) may have forward-looking orientation if, e.g., they aspire to future repair. While feeling resentment may be an experience that re-orients the subject toward the future, it is paradigmatically backward-looking in that it shapes the future as a reparation of past wrongs. I would like to thank a referee for pressing this point.
} 
bystander, as well as any other member of the moral community, irrespectively of their role or special relationship to the distressed. The deontic scope of moral distress is thus broader and more open-ended, to the extent that it engages with others insofar as they can enter a new dynamic interaction as moral providers.

Second, and relatedly, while moral distress articulates a demand for normative attention, such a demand is not necessarily compensatory and remedial. A person who is in distress stands in need of consolation and normative support, not necessarily because he is in the process of counteracting the damage inflicted, compensating a loss, or repairing an impaired relation. This is to say that moral distress articulates a forward-looking generic demand of normative attention, rather than a specific request of compensation or reparation of a specific past wrong. ${ }^{16}$ Unlike blame or resentment, which are addressed to wrongdoers, moral distress builds upon the subject's social vulnerability and susceptibility to others as moral providers. It opens to others, and its success depends upon how others respond in their turn.

Third, while mora distress does not track wrongs, it is deontic, in the sense that Strawson emphasized, and in Sec. 6 we will see that that it qualifies as a category that belongs to the domain of justice. ${ }^{17}$ The relevant contrast between moral distress and reactive attitudes, such as resentment for past wrongs, is not that the former, as opposed to the latter, carves a non-deontic normative space within the large web of moral relations. Rather, the main difference is that the expression of moral distress targets others as moral providers, that is, as interlocutors who are susceptible to the normative needs of others and capable of giving normative attention. Under this description, moral distress counts as a reactive attitude in the same sense in which resentment and blame do because it responds to others as persons with a will, who are hence endowed with moral powers. It is distinctive, however, in that it also engages with such moral powers in a constructive and forward-looking way, by articulating the moral demands of normative attention that are not necessarily remedial and backward looking. ${ }^{18}$ Unlike resentment and blame, moral distress represents a deontic variety of reactive attitudes that builds upon the normative response of others as moral providers who are susceptible to social suffering and capable of emotional engagement.

Finally, the kind of reactivity that is distinctive to this sub-category of reactive attitudes is normative, and therefore it should not be confounded with any causal or tracking relation. Unlike unqualified pain and other purely expressive forms of suffering, the category of moral distress articulates a demand for normative attention, which is addressed to others as moral providers and seeks a normative response from them. In this sense, moral distress is generative, in that it changes the normative relations between the distressed individuals and their audience (i.e., the members of the moral community at large), through emotional engagement. The details of such changes depend on the specific features of the contexts, but the aim of moral distress is to recruit a partner by burdening the audience with the demand: 'May you help?'. There are different ways in which a responsive audience becomes engaged;

\footnotetext{
${ }^{16}$ Normative expectations are largely taken to overlap with demands, Wallace 1994, Walker 2006, 26. By contrast, Macnamara defines normative expectation in a more generic way, as "the stance that leaves us susceptible to the reactive attitudes", Macnamara 2013, 149 n11. This definition is useful for the treatment of moral distress.

${ }^{17}$ The deontic import will be more explicit in Sec. 6. There might be non-deontic normative expectations regarding moral ideals and ideals of character, which are the appropriate target of appellative or aretaic reactive attitudes, as argued by Mason 2017, pp. 155-57, 166-67.

${ }^{18}$ There are different construals of demands, cf. Darwall 2006, Wallace 2019, Macnamara 2013, and McKenna 2013.
} 
they may take a compassionate and supportive attitude toward the sufferers' interests and concerns, by sympathizing or resonating with them. The point here is that the responsive audience becomes engaged in a deliberative plan: 'How may I help?'. The proper setting in which to take up this question is in a normative discussion that addresses the grounds of moral distress, and establishes the content and scope of more specific duties.

\section{The Moral and Epistemic Value of Moral Distress}

An advantage of construing moral distress as a variety of reactive attitudes is that it allows us to better comprehend its deontic and epistemic import. It is generally assumed that a defense of the moral and cognitive significance of the subjective emotional experience commits one to arguing for its evidential import. Feelings are often opaque, deceptive, or easily misunderstood by others, and thus the cognitive import of moral distress is always questionable. Yet there seem to be many situations in which granting the cognitive value of the subjective experience of moral distress is the only way to establish that there has been a genuine breach of justice. Furthermore, some have argued that the appeal to moral distress in the victims' own terms is the only appropriate basis from which to identify wrongs that are not mapped by the moral principles of a given community, either because they target subjects that are made invisible by the extant distribution of social power, or because the acts themselves are hardly recognizable within the normative framework of a given normative community (Fricker, 2007, Renault 2019). Thus far, this discussion has focused primarily on the evidentiary import of moral distress and has been based on the tacit assumption that hurt feelings count as evidence of wrongs or they do not count at all. My contention is that the categorization of moral distress in terms of reactive attitudes represents a decisive step toward an alternative account of its normative and epistemological significance that refocuses the discussion on the web of normative practices that governs the dynamics of moral consideration and mutual recognition.

Like all other feelings, hurt feelings can be misplaced. For instance, they may be based on misrepresentations of what has happened and what was done, or they can be misguided emotional articulations of the context. As reactive attitudes, hurt feelings can fail to meet the criteria of appropriateness for being genuinely expressive, communicative, and normative. A philosophical account of specific normative failures cannot do without a normative theory of right and wrong, but the categorization of hurt feelings as reactive attitudes provides some broad guidelines regarding two main categories of failures. Understood as reactive attitudes, hurt feelings of moral distress are subject to criteria of appropriateness, which do not solely concern the subject's epistemic hermeneutical and testimonial credibility - that is, whether they are reliable and trustworthy in their interpretative rendering of their own feelings and of the situation that calls for them. The subject may press unwarranted claims, or she may fail as a claimant. The Strawsonian account entails that the abstract moral community is unified by a shared view about the norms which govern some fundamental varieties of self-understanding and self-governance of the claimants insofar as they are endowed with rational and moral capacities. Thus, at least some disagreements about what counts as a wrong, and why one has the proper status to claim normative attention from others, are foundational; they pertain to the very constitution of the normative community. The distressed subjects may have no moral standing to press claims; or they may mischaracterize 
their experience entirely by the normative standards of the very community to which they themselves belong as moral agents.

The possibility of subjective failures is not the main reason that claims are contestable. Claims of moral distress are rationally contestable because they stand in need of validation by the normative rational standards of the moral community. Reasons of justification are addressed to others as fellow participants in the normative practice, and so the responsibility to supply justifications are reciprocal, and are a matter of mutual accountability. The characterization of hurt feelings as reactive attitudes belonging to the practical stance of the active members of the moral community re-orients the discussion of the normative significance of the subjective experience in the forensic terms of the burden of proof, moving it away from the analogy with the role that evidences play in empirical inquiries. In particular, this characterization refocuses on normative practices that are grounded on the normative expectations of mutual regard and recognition. From this perspective, the question of the burden of proof is addressed as the normative problem of what we owe to one another, rather than as the problem of correctly representing the facts of the matter.

\section{The Case of Micro-aggressions}

The appeal to the subjective experience is a central matter of dispute in ethical theory and epistemology, but it does posit a formidable challenge in those debates in which the experience of distress is deemed to be crucial to the appraisal and determination of wrongs. For instance, in the case of micro-aggressions, the victims' moral distress may be the only basis for denouncing wrongs. In such circumstances, the matter seems to be whether the victims' appeal to moral distress is enough to ground their allegations. The difficulty in establishing the cognitive value of moral distress partly depends on social bias and prejudices against the hermeneutical and testimonial reliability of victims. However, the category of moral distress defended in Sect. 1-4 may be usefully deployed to reconceive the epistemic role of the appeal to the subjective experience of moral distress.

As a pre-philosophical term, micro-aggression names comments, attitudes, or actions that subtly and often unconsciously attack others, or express prejudiced attitudes toward members of marginalized groups. There is no shared philosophical definition of microaggressions, but the available accounts share a causal framework and converge on taking the import of the appeal to the subjective experience of victims to be evidentiary. ${ }^{19} \mathrm{~A}$ driving concern in the debate about micro-aggressions is to establish how the victims can discharge the burden of proof, given that they can appeal solely to their subjective experi-

\footnotetext{
19 Some opt for a transgressor-centered definition of micro-aggression, which refers to the (often unconscious) mental states that cause the act of micro-aggression, thus allowing for mixed cases in which the transgressor is well-intentioned but biased or culturally insensitive and, thus, susceptible to be misinterpreted. A more promising definition is recipient-centered and refers to the phenomenological experience of the victims as a causal consequence of the act, allowing for large variation across different subjects. For hybrid definitions, which result from different combinations of the models above, see McClare and Rini 2020. Some other definitions are systemic-centered and track the functional role of micro-aggressions within an oppressive social system, with multiple causal realizers. Finally, there are hybrid definitions, which result from various combinations of the previous definitions. Rini (2020) holds that the psychological and structural definitions make the disagreement among different perspectives irresolvable, and that the experiential definition avoids the epistemic problems but renounces objectivity, while hybrid structural definitions face problems for the complexity of social systems Cf. also McClure 2020, and McTernan 2018.
} 
ence. There are two sides in this debate. Some hold that victims know better than anybody else about their being wronged: the appeal to the subjective feelings suffices to provide adequate grounds because the victims have superior epistemic authority, due to their privileged epistemic position. The experience of marginalized members is thought to be more authoritative (Fatima 2020), or more reliable (O'Dowd 2018, 1230). Others dispute that micro-aggressions can be validly assessed using only respondents' subjective reports about feeling wronged. ${ }^{20}$ Both sides discuss the matter in terms of the "accuracy" of the victims' report, ${ }^{21}$ and the discussion is largely informed by the view that the appeal of subjective emotional experience is either evidential or useless. The former position is undermined by the objection that members of marginalized groups tend to be less reliable due to their 'negative emotionality', which produces phenomena of "perceived victimization", (Lelienfeld 2017, 153). The latter discounts the studies that support the contrary view regarding the reliability of the victims' testimony. It seems, then, that focusing on the experience of the victim leads to untreatable disagreements about the source of epistemic authority, and how the burden of proof can be discharged.

A more fruitful way to capture the cognitive import of moral distress exploits the view that hurt feelings express, communicate, and press demands of normative attention and recognition of normative standing. To this purpose, let us consider the following four examples:

Gentle mockery A chubby teenager feels wronged by his classmates who tease him because of his size. Parents and teachers do not consider the reported episodes serious enough to constitute a wrong; after all, funny nicknames display affection.

Rushing An old man affected with dementia is slowed down in his speech. His loving wife often hurries up in his help, by talking in his place. To smooth the conversation, she often finishes his sentences, corrects him when he stumbles, and fills in when he stops in search for words. While he is appreciative of his wife's loving attention, the man resents being overstepped, is ashamed of his condition, and feels humiliated for his loss of skills.

${ }^{22}$ Gate-keeping A scholar feels excluded from the debate about a research program that she helped establish. Over the years, she loses confidence in her intellectual capacity to make any substantial contribution. She feels wronged that her potentiality has been wasted while she was fighting for inclusion.

\footnotetext{
${ }^{20}$ Lilienfeld (2017) objects that the micro-aggression research program is based on negligible support and, disputes that micro-aggressions exert an adverse impact on recipients' mental health, which would be a reasonable ground for considering them harmful and wrong. Lilienfeld also denies that the concept can be made operational in real world and laments the absence of connection of this research program to empirical psychological science, (e.g., psychometrics, social cognition, cognitive-behavioral therapy, behavior genetics, and personality, health, and industrial-organizational psychology).

${ }^{21}$ Notice that the reliability condition on knowledge can be formulated in a minimalist way and does not commit to any substantive account of knowledge, see McGrath 2011, 217.

${ }^{22}$ Established studies in social psychology recognize that these 'small actions' have severe disempowering effects, which aggravate some symptoms and add others (excess disability). For a map of attitudes toward persons with Alzheimer and dementia, according to the observational method of the Dementia Care Mapping, see Kitwood 1997, 46-47. Kitwood defines dementia as a process to be characterized in 'dialectical terms' and remarks that its evolution importantly depends on the person-undermining effects of the web of personal relations and social practices, Kitwood 1997, 5.
} 
Invalidating A couple of unknown artists feel that their work does not get the adequate exposure and visibility compared to other artists who are served by the same agency, due to some suspiciously recurrent incidents, such as the inversion of the alphabetic order of the names in the brochure and typographical errors in the reproductions of their works. Their complaints are met with disbelief, since everybody thinks that these are innocent mistakes, and they feel doubly wronged.

This is an atypical set of examples, in that they are not straightforward cases of social discrimination, implicit bias, or social stereotypes. The reason for this choice is to point to the elusiveness, in the case of micro-aggressions, of the action description under assessment. These samples help us see that we need a diversified explanatory account of the elusiveness of action description. In the first example, the description crucially depends on subtle details, that is, the non-performative features. Whether mockery counts as an insult may depend on noting a grimace, or a playful tone of voice, which hardly counts as a compelling glimpse of truth, and whose moral salience may be difficult to assert. This sort of microaggression is aptly characterizable as a petite action. ${ }^{23}$ This characterization highlights that the feature relevant for moral assessment is the manner in which the action was executed rather than its outward performance. Micro-aggressions are wrong for the same reasons why aggressions are wrong: they are failures to respect others as having equal normative standing. However, differently than categories of performative wrongs, the relevant description of micro-aggressions does not identify a clear-cut performance. The difficulty in figuring out the proper description of the action explains why at least some kinds of micro-aggressions are easily ignored, and do not attract blame (or other negative reactive attitudes) unless the evaluator is in the position of the recipient (hence, suffering from the wrong) or emotionally resonates with the recipient's concerns (e.g., by sympathy or emotional contagion). In the second example, there is a similar ambiguity with regard to the intentionality of the relevant actions, and thus the cognitive value of the victim's moral distress may be questioned. The old man's distress reacts to actions that are performative, but it is not clear that they are the manifestation of any ill-will on the part of his wife. In the third and fourth examples, the difficulty is that the performative acts that elicit moral distress do not seem to be 'actions' that imputable to the will of particular agents; furthermore, they do not easily fall under socially enforced moral principles. There is no moral principle prohibiting the inversion of alphabetic order or gatekeeping.

These explanations of the elusiveness of the action-description may combine to explain how some varieties of micro-aggressions may go unnoticed, independently of social bias. If so, some kinds of micro-aggressions can occur pervasively, and are not confined to the contexts of normalized wrongs. They are easily interpretable as inadvertent mistakes rather than as malevolent actions or self-serving schemas. In all such cases, the burden of proof falls entirely on the victims, and the question of how to understand and assess the value of their subjective experience arises. Subjects do have an obligation to justify their allegations against others, but in these cases, it is particularly hard to comply with the request to meet the onus probandi, since the parties in the dispute do not share the description of the action under assessment. How can the victims succeed in delivering a persuasive proof of their allegations, if their only evidence is their hurt feelings? It seems an impossible task.

${ }^{23}$ See Rorty 1988, 287 ff. Unlike Rorty, I think the case for petites actions is no argument against principled ethics, but it shows the limits of understanding actions as mere performances. Reference to the manner of execution is part of the action description specified in the content of a universal principle. 
The proposal advanced in Sect. 1-4 provides the basis for arguing that this is the wrong question to ask. The problem is not how to ascertain whether these subjects are credible or how to determine that they have been really wronged, given that the only evidence is their distress. The distressed are not witnesses reporting crimes: they are claimants. The subjects in the examples above turn to others to express their hurt feelings not in order to faithfully report an internal experience or to communicate to others how they feel about something that has occurred to them, but rather to press the case that they stand in need of normative attention and to demand recognition for it. The feeling of being wronged grounds a normative claim as much as the need for normative attention this can and should be articulated and disputed in the context of a normative discussion.

An advantage of this approach to the epistemic value of hurt feelings is that it shifts the debate regarding the victims' epistemic authority from a static approach in which the victims are audited and investigated about the epistemic credentials of their report to a dynamic normative interaction between the claimants and their relevant normative community at large. This dynamic approach transforms the problem of the epistemic authority of victims and their epistemic (privileged or defective?) access to the world into the problem of the negotiation dynamics within the moral community. The claimants do have normative authority, not in the sense that they can indefeasibly demonstrate wrongdoing by expressing distress, but in the sense that they have the authority to initiate a normative discussion about what people owe to one another within the bounds of the moral community. This is not to say that the expression of moral distress necessitates a normative discussion. There might be many reasons that, in concrete circumstances, a normative discussion may abort. For example, the addressee may be insensitive to the claimant's distress or be unavailable or unwilling to enter any discussion. Or, they may have other priorities because they do not have infinite attentional resources to allocate. However, these particular circumstances do not defeat the thesis that the claimants have the authority to initiate a normative discussion or that the expression of moral distress provides a way of engaging others in a normative discussion that is aimed at soliciting or requesting moral support. This thesis is related to the reasons-sensitive nature of reactive attitudes. ${ }^{24}$

This dynamic approach also allows us to recognize the moral value of suffering in its own right, rather than as an evidence of something else (i.e., the normative fact of moral violation). In some cases, it is apparent that the very fact that the subjects feel wronged constitutes a sufficient reason for intervention. This is true for the case of the teenager: the parents and teachers have a duty to protect him, regardless of whether they agree that he suffered a serious wrong. In other cases, moral distress may have some deontic power, though insufficient to determine specific duties to relieve distress.

Finally, this dynamic approach points to a specific normative function of moral distress that is directly related to its practical-cognitive value. The experience of distress can be appealed to as a normative prompt for instructing a normative discussion. That is, it provides a reason to engage in the normative discussion; it does not work merely as a trigger or enabler. Before a normative discussion is entered, moral distress merely grounds a generic demand of normative attention that targets moral agents as moral providers. At

\footnotetext{
${ }^{24}$ I think that the relevant notion of normative discussion is dialogical, in contrast to other notions that reduce discussion a sort of "imaginative rehearsal", cf. Gibbard 1990, 75. A full account of the dialogical conception of normative discussion would require us to enter a debate about the norms of practical reasoning, which is beyond the scope of this paper.
} 
this early stage, the generic duty to moral attention does not amount to a duty to relieve distress in specific ways, nor does it burden anyone specifically. There is a generic duty to pay moral attention and consideration that applies broadly to others as moral providers, and even though they have not contributed to the wronging of the victims. When the audience is responsive, this is the starting point for a normative discussion regarding the grounds of moral distress. Possessing the normative standing to press claims does not guarantee that the specific requests pressed are well placed. This is not because subjects are unreliable, fallible, or self-deceptive. Rather, it is because moral claims are essentially contestable: the assessment of the proper grounds for distress and the legitimacy of the subjects' specific requests, as well as the definition of the scope of duty, depends on the results of normative discussion. To this extent, the deontic power of the expression of moral distress is rather limited and undetermined in its scope. Yet it is arguable that the expression of moral distress grounds a generic normative duty that is independent of the grounds on which the claimants might base further and more specific demands. In the next section, I expand on this characterization of the deontic power of moral distress.

\section{Misguided Moral Distress}

Here I shall present the case in which the claims grounded on moral distress are misplaced, and argue that even in this case, its expression has some deontic power. Sally - a middleaged single mom - lost her job as a singer during the pandemic and struggles to find another one. Her social life has been severely curtailed in the last few months and her prospects are dire. When she looks around her, she sees people who are more fortunate, more successful, more loved. When she looks back onto her past, she has a growing sense of having been wronged and undermined in the projects of her youth, unsupported in her choices, not helped when she was in need, and having been robbed of chances and opportunities. Sally's distress results from a mixture of subjective elements that may be invoked to discount the value of her experience of being wronged: her trying external circumstances, her deep sense of insecurity, and profound dissatisfaction with her prospects, her lack of appreciation for assistance she did receive, and her tendency to compare herself unfavorably to others, all of which also make her unappreciative of any good fortune she had. These subjective features conjure up a description that reveals how Sally lacks gratitude toward her moral providers, rather than being as a victim of serial wrong doing.

While Sally's feelings of having been wronged are largely misplaced, her distress is morally relevant, and it posits pertinent questions regarding what to do with it. None in particular individual is at fault for her condition, and she is nobody's personal responsibility; and yet, this does not extinguish the normative question about the proper response to Sally's distress. This is because moral distress does not engage others as wrongdoers, but as providers of moral consideration and attention-especially, but not necessarily, in the aftermath of wrongdoing.

By focusing on the request of normative attention, we can appreciate several aspects that would otherwise be unnoticeable. Sally's distress is morally relevant, whether or not she is misrepresenting her situation or not. That is, the expression of moral distress provides a prima facie reason to enter a normative discussion on proper grounds. The aim of the discussion is to establish whether the requests and allegations afforded are rationally justified. 
Importantly, the normative discussion may concern the scope of moral distress, the grounds of the requests made, and the normative standards by which they are assessed. In the context of a normative discussion, the appeal to Sally's moral distress may have a significant normative impact; for instance, it may lead her interlocutors to uncover inconsistencies or deficiencies in the normative standards adopted by the concrete normative community. This is another sense in which moral distress is generative beyond its capacity to ground a generic duty to give normative attention to the distress, because it potentially impacts more broadly on the normative structure of a given community. It may instruct a normative discussion that calls the specific normative criteria for the assessment of the proper grounds for moral distress into question, which, until then, would have been taken for granted. This effect can be illustrated by elaborating on Sally's example.

The fact that nobody in particular is at fault for Sally's distress does not mean that her experience of being wronged is not genuine. In fact, her distress may call attention to a particular form of injustice, insofar as it responds to the moral community as a collective rather than to individuals, redirecting complaints and requests to the entire social network rather than to anyone in particular, or to members and representatives of the community, rather than to particular individuals. On this understanding, we can see that Sally's moral distress forces her audience to reconsider the distribution of duties and responsibilities within the moral community as such. It is arguable that at least some of the moral responsibility to relieve a moral agent's distress should be understood systemically, and distributed across the network, rather than grounded in dyadic personal relations that bind victims and transgressors. ${ }^{25}$ At least in some cases - some of which may perhaps be only partly analogous to Sally's - the duty to relieve moral distress is a matter of institutional justice rather than an obligation of benevolence that applies to virtuous agents. This is an important consideration for keeping open the prospect that the modality of moral distress as a reactive attitude is deontic rather than appellative or aretaic, as argued above. ${ }^{26}$

Further to this, to say that moral distress is a reactive attitude with deontic import does not mean that it proves that an individual or an institution is at fault in the fulfillment of moral duty. Rather, it indicates that a subject who is emotionally responsive to normative failures and wrongs, an active participant of the moral community, who is somebody with the same normative standing as moral agents, is calling for- is demanding normative attention. This call for attention generates a duty of moral consideration that would be wrong to disregard. Disregarding that demand would ingenerate a situation of normative abandonment, which is likely to corrode the claimants' self-respect and their moral powers. ${ }^{27}$ Argu-

\footnotetext{
${ }_{25}$ Friedlaender (2018) argues that "the cumulative harm of micro-aggressions presents a unique case for understanding disaggregation models for contributed harms, blame allocation, and individual responsibility within structural oppression", holistically, and so, all have a responsibility to respond to the cumulative harm to which they have individually contributed. By contrast, I am inclined to say that in a normative web based on specialized functions and roles, such responsibilities are to be distributed across different agents and institutions.

${ }^{26}$ Cf. Mason 2017, pp. $155 \mathrm{ff}$.

${ }^{27}$ On the double wrong of normative abandonment, see Walker 2006, 95, 205, 209. Fatima (2020) argues that micro-aggressions diminish the victim's ability to generate and participate in making knowledge claims. She distinguishes the primary (direct) harm of micro-aggressive acts and the secondary epistemic harm that occurs in the aftermath of the micro-aggression, such as, in particular, the distrust or loss of credibility that victims face in relating their experience to others, cf. Fricker 2007. In my view, epistemic wrongs belong in the category of violations of recognition-respect for others, and it is more productive to treat them as such rather than as an independent category of wrongs.
} 
ably, in a moral community, moral agents are bound by the obligation to protect and sustain each other's capacities for moral agency and moral interactions, and so there is a general duty to relieve others from moral distress.

The recognition of a generic demand of attention does not commit the (sensitive, compassionate, sympathetic) audience to anything further regarding the specific requests afforded by the claimant, and their grounds. To this extent, the deontic power of moral distress is limited in its domain; and it is indeterminate, but very broad in its scope of application, since it applies to all agents endowed with moral powers. Furthermore, the breadth of the scope of application indicates another interesting peculiarity of the deontic import of moral distress: the normativity of the generic duty to attention remains intact in the case that the subjects' claims are not just misplaced, but morally misguided. Suppose that Sally's allegations are largely driven by envy. Does the fact that her moral distress originates in envy rule out her claims, undermine their moral value, and deprive them altogether of normative significance? While envy does not disqualify Sue's claims to normative attention, but it is instructive to consider whether and how this emotion contributes to circumscribing the deontic power of distress. Envy indicates an incapacity to empathize and rejoice with others or to sympathize with them for their good fortunes. To be sure, envy is a defective trait of character, but it brings the depth of social vulnerability to the fore; it reveals that people are susceptible to wrongs merely by being compared and contrasted to others, and more acutely so in competitive contexts. Besides the malevolence or negligence of individuals, distributive arrangements can also result in one being threatened, infringed upon, or undermined in one's wellbeing. In this particular construal of Sue's case, moral distress responds to a community as a collective of agents with moral powers, rather than to the quality of the will of individuals. Some forms of injustice result from particular structures of personal relations and social organizations that undermine the individuals' moral standing and their practical capacities and particularly affect their self-respect and self-esteem. ${ }^{28}$

In such circumstances, the capacity for moral distress enables agents to understand that (and how) their chances of social integration and self-realization are undermined and allows them to attract normative attention and possibly retrieve social resources to gain a more favorable position within the social schema, or else to coopt others in the revision of such schema. Thus, the category of moral distress as a reactive attitude does not serve only as a diagnostic tool to map the varieties of moral and social vulnerabilities, but it constitutes a decisive mode of ethical and political empowerment.

\section{Concluding Remarks}

I have argued that moral distress is best understood as a reactive attitude, with a distinctive reactivity, that is markedly forward-looking and generative. On this construal, the capacity for moral distress is vital to the exercise and development of moral agency; it is crucial for gaining or regaining full normative standing. To this extent, it pertains to the dynamics of

\footnotetext{
${ }^{28}$ In advocating moral distress as a category of justice, I am thereby rejecting the view that it pertains to the deontic domain of imperfect duties of benevolence, although I agree that the duties arising from moral distress regarding moral attention cannot be externally enforced. The duty to pay attention to the distressed is a duty to respect others as moral agents.
} 
recognition and empowerment. To conclude this argument, I would like to submit two ways in which the account of moral distress defended here can be further developed and deployed.

First, qualified as a distinctive reactive attitude, the category of moral distress can be adopted to enhance theories of justice that are based on the principles of practical reason. Emmanuel Renault has recently argued that such theories make the distress of the most vulnerable subjects "politically inexpressible" in the space of institutionalized politics (Renault 2019, 33, 45), because they model moral membership on large corporations (Renault 2019, 44). ${ }^{29}$ His argument builds upon a contrast between methods that rely on the experience of injustice in articulating the demands of recognition, and methods that rely on normative principles selected from an ideal standpoint (Renault 2019,36, 46). The objection is that the latter are conservative because of the idealization in place. ${ }^{30}$

A full reply should be able to demonstrate the constructive and transformative function of universal principles in the process of practical reasoning and normative discussion; it should also point to the potentialities of appealing to constructive principles of practical reasoning in theorizing about justice. ${ }^{31}$ This is a large endeavor that lies well beyond the scope of this paper. However, the proposal advanced here could be usefully recruited in service of such theories and prove decisive in showing that the capacity for emotional responsiveness to and engagement with others is constitutive of practical reason and moral agency. Understood as a capacity contributive to the exercise of moral agency, moral distress figures prominently among the emotional dispositions that make us susceptible to moral norms. Such an account would improve the prospects of appealing to the structural principles of practical reason in accounting for a crucial set of phenomena that pertain to the dynamics dimension of practical reason, such as normative discussion, normative guidance, and more importantly, the normative revisions appropriate for building an open-ended moral community. ${ }^{32}$

Second, this proposal regarding emotional reactivity may be placed in meta-ethical disputes about the experiential contribution to moral knowledge. It concurs with the view that the world does not provide feedback about whether one has applied the correct concepts, and so experience gives no genuine opportunity for "calibrating one's moral judgments". ${ }^{33}$ It does not, however, discount the role of others in an objectivist account of moral knowledge. In fact, this paper contributes to this debate by providing a distinctive characterization of the role of others in terms of their emotional responsiveness and engagement. Others play a constitutive role in the validation of moral judgments, not because their actual opinions or subjective experience serve as guardrails, but because they have equal normative standing in the moral community. Thus, it is a mistake to conceive of the contribution of others in the guise of an external checking to our moral opinions, as if moral judgments should be adjusted against other people's opinions as much as against other external factors, or features of the world. ${ }^{34}$ By contrast, the contribution of others is dialectical, and it is at work

\footnotetext{
${ }^{29}$ These objections are moved against J. Habermas and J. Rawls. Notice that the fact that moral principles are compatible with injustice does not prove that they are false; it only proves that they are too indeterminate to exclude all form of injustice.

30 Rawls 1971, cf. On the distinction between abstraction and idealization, see O'Neill 1989. On Rawls' claims about the priority of ideal theory, see Valentini 2012.

31 See e.g., Rawls 1971, 1999, Baldwin 2013, Richardson 2018.

32 This is not the place to offer a positive account of such an appeal, but see Bagnoli 2021.

${ }^{33}$ By contrast, see McGrath 2011, 119-20; Jacobsen 2005, 400.

${ }^{34}$ McGrath 2011, 121-22.
} 
already in the very activity of rational justification. At this level, the recognition of others as peers constrains the content of the moral principles they can share. In some paradigmatic cases, moral principles are finessed by pressing and accepting the demand that moral distress receive normative attention, and on further grounds, be relieved. ${ }^{35}$ In such cases, facing the moral distress of others is the first step in the normative process of normative negotiation, which leads to revising previously shared moral principles, broadening their scope, or reconceiving them anew. To this extent, moral distress should be acknowledged as a normative drive in the practices that leads to an inclusive and open-ended normative community. ${ }^{36}$

Open Access This article is licensed under a Creative Commons Attribution 4.0 International License, which permits use, sharing, adaptation, distribution and reproduction in any medium or format, as long as you give appropriate credit to the original author(s) and the source, provide a link to the Creative Commons licence, and indicate if changes were made. The images or other third party material in this article are included in the article's Creative Commons licence, unless indicated otherwise in a credit line to the material. If material is not included in the article's Creative Commons licence and your intended use is not permitted by statutory regulation or exceeds the permitted use, you will need to obtain permission directly from the copyright holder. To view a copy of this licence, visit http://creativecommons.org/licenses/by/4.0/.

\section{References}

Bagnoli C (2021) "The Objective Stance and the Boundary Problem", European Journal of Philosophy, special vol. The Struggle for Recognition and the Second Person, in Thomas Khurana (ed.), 29/3 (2021), doi https://doi.org/10.1111/ejop.12678

Baldwin T (2013) “Constructive Complaints”, in C. Bagnoli Ed., Constructivism in Ethics (201-220). Cambridge University Press

Bennett J (1980) Accountability. In: van Straaten Z (ed) Philosophical subjects: Essays presented to P.F. Strawson (pp. 14-47). Oxford: Clarendon Press

Darwall S (2006) Darwall, the Second-person Standpoint: Morality, Respect and Accountability. Harvard University Press

Darwall S (2013) Morality, Authority, and Law: Essays in Second-Personal Ethics I. Oxford University Press

Fatima S (2020) I Know What Happened to Me: The Epistemic Harms of Microaggression. In Jeanine Weekes Schroer \& Lauren Freeman (eds.), Microaggressions and Philosophy. Taylor \& Francis. pp. 163-183

Fricker M (2007) Epistemic Injustice. Oxford University Press

Friedlaender C (2018) On Microaggressions: Cumulative Harm and Individual Responsibility. Hypatia 33(1):5-21

Kitwood T (1997) “How Personhood is Undermined”. In: Dementia Reconsidered. Open University Press

Lilienfeld SO (2017) "Microaggressions: Strong Claims, Inadequate Evidence”, Perspectives on Psychological Science. 2017;12(1):138-169

Macnamara C (2013) Taking Demands Out of Blame. In: Coates DJ, Tognazzini NA (eds.) Blame: Its Nature and Norms. New York, USA: Oxford University Press. pp. 141-161

Mason M (2017) Reactive Attitudes and Second-Personal Address. In: Remy D, Karsten S (eds.) Ethical Sentimentalism. Cambridge University Press, pp. 133-152

McClure Emma RR (2020) "Microaggression: Conceptual and scientific issues", Philosophy Compass, 15 (4)

McGeer V (2012) “Co- Reactive Attitudes and the Making of Moral Community." In Emotions, Imagination, and Moral Reasoning, edited by R. Langdon and C. Mackenzie, 299- 326. New York: Psychology Press

\footnotetext{
${ }^{35}$ For alternative views of the constructive role of principles of practical reason, cf. Baldwin 2013, Richardson 2018 .

${ }^{36}$ An abridged version of this paper has been presented as a keynote address at the MANCEPT workshop on "Moral and Socio-Political Progress", held on Sept. 8 2021; I would like to thank its organizers and audience, three external journal referees, and the editors of this issue, for their constructive criticisms and suggestions. I would like to thank the University of Oxford for supporting this research during my first term as a Visiting Fellow at All Souls College.
} 
Mcgrath S (2011) Moral Knowledge and Experience. Oxford Studies in Metaethics 6:107-127

McTernan E (2018) Microaggressions, Equality, and Social Practices. Journal of Political Philosophy 26(3):261-281

O’Dowd O (2018) Microaggressions: A Kantian Account. Ethical Theory Moral Practice 21:1219-1232

O’Neill O (1989) Constructions of Reason: Explorations of Kant's Practical Philosophy. Cambridge University Press.

Rawls J (1971) A Theory of Justice. Harvard UP.

Rawls J (1999) Collected Papers. Samuel Freeman Ed, Harvard

Renault E (2017) Social Suffering. Rowan and Littlefield

Renault E (2019) The Experience of Injustice: A Theory of Recognition. Columbia University Press

Rini R (2021) The Ethics of Microaggression. Routledge

Rorty A (1988) Mind in Action, Boston

Strawson PF (1962) "Freedom and Resentment." Proceedings of the British Academy 48: 187-211

Valentini L (2012) Ideal vs. Non-ideal Theory: A Conceptual Map. Philosophy Compass 7: 654-664

Walker MU (2006) Moral Repair. Cambridge University Press

Wallace RJ (1994) Responsibility and the Moral Sentiments. Harvard University Press

Watson G (1987) 4. Responsibility and the Limits of Evil: Variations on a Strawsonian Theme. In: Fischer JM, Ravizza M (eds.) Perspectives on Moral Responsibility. Cornell University Press. pp. 119-148

Publisher's Note Springer Nature remains neutral with regard to jurisdictional claims in published maps and institutional affiliations. 